\title{
n-Alkane Binary Molecular Alloys
}

\author{
D. Mondieig, ${ }^{*}+$ F. Rajabalee, and V. Metivaud \\ Centre de Physique Moléculaire Optique et Hertzienne, UMR 5798 au CNRS-Université \\ Bordeaux I, F-33405 Talence Cedex, France \\ H. A. J . Oonk ${ }^{\dagger}$ \\ Chemical Thermodynamics Group, Debye Institute, Faculty of Chemistry, Utrecht University, \\ Padualaan, 8, $3584 \mathrm{CH}$ Utrecht, The Netherlands

\section{A. Cuevas-Diarte ${ }^{\dagger}$} \\ Departament de Cristal·lografia, Universitat de Barcel ona, Martí i Franquès, \\ E-08028 Barcel ona, Spain
}

Received November 19, 2003

\begin{abstract}
The experimental systems considered in this paper are normal alkanes, in the range from octane to octacosane; and their binary mixtures $\{(1-x)$ mol of $\mathrm{CnH} 2 \mathrm{n}+2+\mathrm{x}$ mol of $\left.\mathrm{C} n^{\prime} \mathrm{H} 2 n^{\prime}+2\right\}$, with $n^{\prime}>n$, and $\Delta n=n^{\prime}-n$ taking the values 1 and 2 . The alkanes and their mixtures have a rich, complex polymorphic nature, for the description of which a distinction is made between a high-temperature and a low-temperature domain. The high-temperature domain is occupied by rotator phases, and the low-temperature domain by a variety of mixed crystalline phases, referred to as the "ordered" phases. Experimental phase diagram data for 19 binaries-including 11 binaries for which original data are presented-are used to give a uniform and coherent description of the phase relationships for the ensemble of alkane alloys.
\end{abstract}

\section{Introduction}

The normal alkanes $\mathrm{CnH} 2 \mathrm{n}+2$ (hereafter denoted by $\mathrm{Cn}$ ) and their mixtures have been studied extensively, during the last 2 decades in particular. The al kanes are the main constituents of mineral oil: for the petroleum industry knowledge of the structural and thermodynamic properties of their mixtures is of vital importance. From a pure-science point of view, n-alkanes and their mixtures are useful model systems for more complex materials, like polymers and biomembranes. In addition, and with regard to practical applications, alkane alloys have proved their value as tuneable phase change materials for thermal protection and storage of energy. ${ }^{1-3}$

The group of $n$-alkanes studied combine a rich, complex polymorphic nature with the existence of a mesostate. The mesostate, between the "normal", ordered solid state $\left(\Phi_{\text {ord }}\right)$ and liquid, is a crystalline state, referred to as rotator $(R)$. In the rotator mesostate the molecules have rotational freedom al ong their long axes. Within $\Phi_{\text {ord }}$ and R several forms (phases) can be

* Corresponding author. Telephone: 00(33)540006988. Fax: 0033540006686. E-mail: d.mondieig@cpmoh.u-bordeaux.fr.

${ }^{\dagger}$ All members of the REALM (Réseau Européen sur les ALliages Moléculaires).

(1) Espeau, P.; Robles, L.; Mondieig, D.; Haget, Y.; Cuevas-Diarte, M. A.; Tamarit, J'. LI. Mater. Res. Bull. 1996, 31 (10), 1219.

(2) Mondieig, D.; Rajabalee, F.; Laprie, A.; Oonk, H. A. J .; Calvet,

T.; Cuevas-Diarte, M. A. Transfus. Apheris Sci. 2003, 28, 143.

(3) Ventolà, L.; Calvet, T.; Cuevas-Diarte, M. A.; Métivaud, V.; Mondieig, D.; Oonk, H. A. J . Mater. Res. Innovations 2002, 6, 284290. distinguished. Mixing of $n$-alkanes generally has a dramatic influence on the polymorphic relationships, in particular, when even ( $\mathrm{n}$ in $\mathrm{Cn}$ is even) alkanes are mixed with odd alkanes. ${ }^{4-20}$

(4) Lüth, H.; Nyburg, S. C.; Robinson, P. M.; Scott, H. G. J . Mol. Cryst. Liq. Cryst. 1974, 27, 337.

(5) Denicolo, I.; Craeivich, A. F.; Doucet, J . J . Chem Phys. 1984 $80,12,6200$.

(6) Gerson, A. R.; Nyburg, S. C. Acta Crystallogr. 1994, B50, 252256

(7) Nouar, H.; Petitjean, D.; Bourdet, J . B.; Bouroukba, M.; Dirand, M. Thermochim. Acta 1997, 293, 87.

(8) Nouar, H.; Bouroukba, M.; Petitjean, D.; Dirand, M. J . Mol. Struct. 1998, 443, 197.

(9) Achour-Boudjema, Z.; Bouroukba, M.; Dirand, M. Thermochim Acta 1996, 276, 243.

(10) J outi, B.; Petitjean, D.; Provost, E.; Bouroukba, M.; Dirand M. J. Mol. Struct. 1995, 356, 191.

(11) Achour-Boudjema, Z.; Bourdet, J . B.; Petitjean, D.; Dirand, M J . Mol. Struct. 1995, 354, 197.

(12) Sabour, A.; Bourdet, J. B.; Bouroukba M.; Dirand, M. Thermochim. Acta 1995, 249, 269.

(13) Nouar, H.; Bouroukba, M.; Petitjean, D.; Dirand, M. Mol. Cryst. Liq. Cryst. 1998, 309, 273.

(14) Nouar, H.; Petitjean, D.; Bouroukba, M.; Dirand, M. Mol. Cryst. Liq. Cryst. 1999, 326, 381.

(15) Dirand, M.; Bouroukba, M.; Chevallier, V.; Petitjean, D.; Behar E.; Ruffier-Meray, V. J . Chem. Eng. Data (Review) 2002, 47 (2), 115.

(16) Métivaud, V.; Rajabalee, F.; Mondieig, D.; Haget, Y.; CuevasDiarte, M. A. Chem. Mater. 1999, 11, 117.

(17) Rajabalee, F.: Métivaud, V.:Mondieig, D.; Haget, Y.; CuevasDiarte, M. A. J . Mater. Res. 1999, 14 (6), 2644

(18) Métivaud, V.; Rajabalee, F.; Cuevas-Diarte, M. A.; Calvet, T.; Mondieig, D.; Haget, Y. An. Quim., Ed. Int. 1998, 94 (6), 396.

(19) Rajabalee, F.: Métivaud, V.; Mondieig, D.; Haget, Y.; Oonk, H. A. j. Helv. Chim. Acta 1999, 82 (11), 1916.

(20) Wurflinger, A.; Mondieig, D.; Rajabalee, F.; Cuevas-Diarte, M A. Z. Naturforsch. 2001, 56a, 1. 
In previous papers we have reported on the phase behavior of a number of individual binary systems. ${ }^{16-20}$ For these systems all mixed phases were characterized as to their crystallographic properties. With regard to the thermodynamic mixing properties, we have demonstrated that, within a given form, alkane mixed crystals satisfy the criteria for "perfect family of mixed crystals". A perfect family has a uniform temperature of excess enthalpy/entropy compensation. In addition, the two excess properties, which are system-dependent, can be correlated in terms of $(\Delta n / \bar{n})$, where, for a binary system $C n+C n^{\prime}, \Delta n=\left(n^{\prime}-n\right)$ and $\bar{n}=0.5\left(n+n^{\prime}\right), n^{\prime}$ $>$ n. 21,22

The primary scope of this paper is to give a global overview of the phase relationships in the binary systems we have studied. The analysis relies on 19 experimental phase diagrams, for systems with $\Delta \mathrm{n}=1$ and $\Delta n=2$, in the range from $n=8$ to $n=28$. Eight of these phase diagrams have been published before. Owing to the regularities in behavior, which make detailed descriptions of individual systems of secondary importance, we prefer to incorporate in this paper our results for the 11 remaining systems.

\section{Materials and Experimental Section}

(a) Materials. The products were purchased either from Fluka or from Aldrich and their purity grades were higher than $99 \%$.

The binary mixed samples were prepared according to the melting and quenching method: the components are weighed in the desired proportions, melted, and mixed thoroughly to obtain an entirely homogeneous sample and then quenched into liquid nitrogen. We have shown that holding mixed samples in a rotator phase has the effect that the $\Phi_{\text {ord }} \rightarrow R$ transition is obtaining an isothermal nature. ${ }^{23}$ For each system at least 10 compositions have been studied.

(b) Techniques. Cal orimetric measurements were carried out using a Perkin-Elmer DSC7 differential scanning calorimeter (DSC) operating in the subambient mode. Transition temperatures and enthal pies were obtained from at least four independent experiments performed on $(4.0 \pm 0.1) \mathrm{mg}$ samples with a scanning speed of $2 \mathrm{~K} \cdot \mathrm{min}^{-1}$. The shape-factor method was used to determine the phase transition temperatures. ${ }^{24}$ The random part of the uncertainties was estimated using Student's method with $95 \%$ of threshold reliability.

I sothermal and function-of-temperature X-ray diffraction analyses (with $\mathrm{Cu} K \alpha$ radiation, $\lambda=1.5406 \AA$ ) were performed using the following:

(i) A Siemens D500 vertical powder diffractometer, which works in the reflection mode with a Bragg-Brentano geometry. About $5 \mathrm{~g}$ of product was put into the sample holder and the data were collected with $2 \theta$ steps of $0.04^{\circ}$ and a time interval of at least $4 \mathrm{~s}$. A thin plate of glass was placed between the sample to be analyzed and the sample hol der, to avoid the diffraction reflections of copper and nickel.

(ii) and (iii) An INEL CPS 120 diffractometer and a Guinier Simon camera, which work in the transmission mode. About $3 \mathrm{mg}$ of product was put in a Lindemann capillary $(0.5-\mathrm{mm}$ diameter) hermetically closed.

The recordings of isothermal and function-of-temperature diffraction analyses allow the determination of the limits of

(21) Oonk, H. A.J .; Mondieig, D.; Haget; Y.; Cuevas-Diarte, M. A. J . Chem. Phys. 1998, 108 (2), 715.

(22) Rajabalee, F.; Métivaud, V.; Oonk, H. A. J .; Mondieig, D.; Waldner, P. Phys. Chem. Chem. Phys. 2000, 2, 1345

(23) Mondieig, D.; Métivaud, V.; Oonk, H. A. J .; Cuevas-Diarte, M. A. Chem. Mater. 2003, 15, 2552-2560.

(24) Courchinoux, R.; Chanh, N. B.; Haget, Y.; Calvet, T.; Estop, E.; Cuevas-Diarte, M. A. J . Chim. Phys. 1989, 86 (3), 561.
Table 1. Crystallographic Characteristics of the Phases of Pure Alkanes (in the Range $n=8$ to $n=28)^{a, b}$

\begin{tabular}{|c|c|c|c|}
\hline phase & observed in Cn & space group & Z \\
\hline RI & $9 \leq \mathrm{n}_{\text {odd }} \leq 25$ and $\mathrm{n}_{\text {even }}=22,24$ & $\mathrm{Fmmm}$ & 4 \\
\hline R॥I & $22 \leq \mathrm{n} \leq 26$ & $\mathrm{R} 3 \bar{m} \mathrm{~m}$ & 3 \\
\hline RıII & 28 & triclinic & \\
\hline RIV & 28 & monodinic & \\
\hline Rv & 23,25 & monoclinic & \\
\hline & $8 \leq \mathrm{n}_{\mathrm{even}} \leq 24$ & $\mathrm{P} \overline{1}$ & 1 \\
\hline M011 & $\mathrm{n}_{\mathrm{even}} \geq 26$ & $\mathrm{P} 2_{1} / \mathrm{a}$ & 2 \\
\hline $\mathrm{O}_{\mathrm{i}}$ & $\mathrm{n}_{\text {odd }}$ & Pcam & 4 \\
\hline $\mathrm{O}_{\mathrm{dci}}$ & $\mathrm{n}_{\mathrm{odd}} \geq 23$ & Pnam & 4 \\
\hline$M_{\text {dci }}$ & $\mathrm{n}_{\text {odd }} \geq 25$ & $\mathrm{Aa}$ & 4 \\
\hline
\end{tabular}

a For $\mathrm{O}_{i}, \mathrm{O}_{d c i}$ and $\mathrm{M}_{d c i}$, the subscript "dc" is for conformational defects and "i" and " $\mathrm{p}$ " are for even and odd, respectively ("impair" and "pair" in French). ${ }^{\mathrm{b}} \mathrm{M} 011$ is one of the Mhkl phases; in this notation (hkl) describes the plane formed by the methyl end groups $\left(\mathrm{CH}_{3}\right)$ in the referential of the orthorhombic subcell.

the single-phase and two-phase regions as well as the crystallographic parameters of the observed alloys.

(c) Polymorphism of the Pure Components. Despite their relatively simple architecture, governed only by van der Waals intermolecular forces, the polymorphism of the normal alkanes is relatively complex. In the range from C8 to C28, the following phase transitions are observed ${ }^{25,26}$ (the symbol $\rightarrow$ is used for first-order transitions and the symbol $--\rightarrow \rightarrow$ for second-order transitions):

\begin{tabular}{|c|c|c|c|c|c|}
\hline $\begin{array}{l}\text { for n even, } \\
\text { c8-c20: }\end{array}$ & $T_{p}$ & $\rightarrow$ & & & Liquid \\
\hline C22 and C24: & $\mathrm{T}_{\mathrm{p}}$ & $\rightarrow$ & $\mathrm{RI} \rightarrow$ & $\mathrm{R} I \mathrm{l} \rightarrow$ & Liquid \\
\hline C26: & M011 & $\rightarrow$ & & $\mathrm{R} ॥ \mathrm{I} \rightarrow$ & Liquid \\
\hline $\begin{array}{l}\text { C28: } \\
\text { for } n \text { odd }\end{array}$ & M011 & $\rightarrow$ & & RIV $\rightarrow$ & Liquid \\
\hline C17-C21: & $\mathrm{O}_{\mathrm{i}} \rightarrow$ & & RI & $\rightarrow$ & Liquid \\
\hline C23: & $\mathrm{O}_{\mathrm{i}} \rightarrow \mathrm{O}_{\mathrm{ddi}} \rightarrow \mathrm{M}_{\mathrm{ddi}} \rightarrow$ & $\mathrm{Rv} \cdots \rightarrow$ & $\mathrm{RI} \rightarrow$ & $\mathrm{R} ॥ \rightarrow$ & Liquid \\
\hline C25: & $\mathrm{O}_{\mathrm{i}} \rightarrow \mathrm{O}_{\mathrm{dci}} \rightarrow \mathrm{M}_{\mathrm{di}} \rightarrow$ & $\mathrm{RV}-\cdots \rightarrow$ & $\mathrm{RI} \rightarrow$ & $\mathrm{R} \| \rightarrow$ & Liquid \\
\hline C27: & $\mathrm{O}_{\mathrm{i}} \rightarrow \mathrm{O}_{\mathrm{dci}} \rightarrow \mathrm{M}_{\mathrm{di}} \rightarrow$ & & RIII -- & $\mathrm{RIV} \rightarrow$ & Liquid \\
\hline
\end{tabular}

The crystallographic characteristics (space group, number of molecules per unit cell, and the signification of the attached subscript) are recalled in Table 1. Two types of solid phase may be distinguished: the ordered forms $\Phi_{\text {ord }}$ (called order ed because they are not affected by orientational disorder) in the low-temperature (LT) domain and the orientational disordered forms (so-called rotator phases Rı, RıI, RıII, Rıv, Rv) which appear before melting, in the high-temperature (HT) domain. More details about the rotator phases can be found in the work of Sirota. 27

Temperatures of transition are given in Table 2, together with the polymorphic sequences. In the table, the phases are arranged in order of their appearance on the temperature scale; their nature is as follows:

(i) $\mathrm{T}_{\mathrm{p}}, \mathrm{O}_{i}$, and $\mathrm{M} 011$ are the most ordered phases.

(ii) $\mathrm{O}_{\text {di }}$ and $\mathrm{M}_{\text {di }}$ are affected by conformational defects. For $n<25$, low-temperature phases are characterized by a low gauche-bond concentration $(\mathrm{m}(\mathrm{g})=0.10 \pm 0.03)$, which is independent of temperature.28

At the $\Phi_{\text {ord }} \rightarrow \Phi_{\text {ord }}$ transitions, the gauche-bond concentration increases discontinuously, slowly for $\mathrm{O}_{i} \rightarrow \mathrm{O}_{\text {dci }}$ and more abruptly for $\mathrm{O}_{\mathrm{dci}} \rightarrow \mathrm{M}_{\mathrm{dci}} \cdot{ }^{30}$ The increase in conformational defects is higher at the $\Phi_{\text {ord }} \rightarrow R$ transitions.

(25) Roblès, L.; Mondieig, D.; Haget, Y.; Cuevas-Diarte, M. A J. Chim. Phys 1998, 95, 92.

(26) Espeau, P.; Robles, L.; Mondieig, D.; Haget, Y.; Cuevas-Diarte, M. A.; Oonk, H. A. J J J . Chim. Phys. 1996, 93, 1217.

(27) Sirota, E. B.; King, H. E.; Singer, D. M.; Shao, H. H. J . Chem. Phys. 1993, 98, 5809.

(28) Kim, Y.; Strauss, H. L.; Snyder, R. G. J . Am. Chem. Soc. 1989, 93,7520

(29) Rajabalee, F.; Negrier, P.; Mondieig, D.; Cuevas-Diarte, M. A. Chem. Mater. 2002, 14 (10), 4081

(30) Maroncelli, M.; Qi, S. P.; Strauss, H. L.; Snyder, R. G. J . Am Chem. Soc. 1982, 104, 6237. 
Table 2. Temperatures (in $\mathrm{K}$ ) and Enthalpies (in $\mathrm{kJ} \cdot \mathrm{mol}^{-1}$ between Brackets) of Phase Transitions ${ }^{\mathrm{a}}$

\begin{tabular}{|c|c|c|c|c|c|c|c|c|c|c|c|c|}
\hline \multirow[b]{2}{*}{$\mathrm{Cn}$} & \multicolumn{6}{|c|}{ ordered phases ( $\left.\Phi_{\text {ord }}\right)$} & \multicolumn{5}{|c|}{ rotator phases } & \multirow[b]{2}{*}{ liquid } \\
\hline & $\mathrm{T}_{\mathrm{i}}$ & $\mathrm{T}_{\mathrm{p}}$ & $\mathrm{O}_{\mathrm{i}}$ & M011 & $\mathrm{O}_{\mathrm{dci}}$ & $M_{\mathrm{dci}}$ & $\mathrm{Rv}$ & RI & RıI & RIII & RIV & \\
\hline $\mathrm{C} 8$ & & - & & & & & & & & & & 216.6 (21.8) \\
\hline C9 & - & & 217.8 & & & & & $218.2(6.2)$ & & & & 219.5 (15.0) \\
\hline C10 & & - & & & & & & & & & & $243.0(27.6)$ \\
\hline C11 & $\bullet$ & & $236.3(0.1)$ & & & & & $237.4(7.0)$ & & & & $247.6(22.5)$ \\
\hline C12 & & - & & & & & & & & & & 263.1 (35.7) \\
\hline $\mathrm{C} 13$ & & & - & & & & & $255.2(7.7)$ & & & & $267.7(28.9)$ \\
\hline C14 & & - & & & & & & & & & & $278.3(42.7)$ \\
\hline C15 & & & - & & & & & 270.3 (8.7) & & & & 282.7 (34.2) \\
\hline C16 & & - & & & & & & & & & & 290.7 (53.0) \\
\hline C17 & & & - & & & & & 284.2 (10.8) & & & & 294.7 (39.4) \\
\hline C18 & & - & & & & & & & & & & $301.1(60.1)$ \\
\hline C19 & & & - & & & & & 294.8 (12.7) & & & & 304.4 (42.7) \\
\hline C20 & & - & & & & & & & & & & 309.7 (68.1) \\
\hline $\mathrm{C} 21$ & & & $\bullet$ & & & & & 304.3 (15.7) & & & & 313.0 (46.6) \\
\hline C22 & & - & & & & & & 315.8 (27.3) & $316.1(<0.3)$ & & & 316.6 (49.1) \\
\hline C23 & & & - & & $310.5(<0.3)$ & & 312.4 (19.6) & 314.2 & $317.9(<0.3)$ & & & 320.2 (52.6) \\
\hline C24 & & - & & & & & & 319.0 (30.3) & $319.6(<0.3)$ & & & 323.4 (53.8) \\
\hline $\mathrm{C} 25$ & & & $\bullet$ & & $310.5(<0.4)$ & $319.4(0.4)$ & $320.0(23.6)$ & 321.2 & $322.6(<0.4)$ & & & $326.4(57.8)$ \\
\hline C26 & & & & - & & & & & 325.0 (32.6) & & & 329.1 (60.1) \\
\hline C27 & & & $\bullet$ & & $312.9(0.3)$ & $322.3(2.5)$ & & & & $325.9(27.1)$ & 327.9 & $331.6(62.8)$ \\
\hline C28 & & & & - & & & & & & & 329.4 (35.2) & 333.4 (63.0) \\
\hline
\end{tabular}

a The phases stable at low temperatures are indicated with the symbol $\bullet$.

(iii) The $\mathrm{R}$ phases are characterized by a high level of rotational and conformational disorder. Three kinds of conformational defects, gt (end gauche), gg (gauche-gauche), and gtg (kink), have been identified. The concentrations of the defects increase with chain length: gt faster than gg and gtg. ${ }^{30}$ All transitions are first-order transitions, with the exception, however, of Rv $\cdots$ RI and RIII $\cdots \rightarrow$ RIV. Details about the thermo-energetic data and structural characteristics of the alkanes, from C8 to C28, can be found in recent papers from our group. ${ }^{25,26,29}$

\section{Results}

(a) Phase Diagrams. The binary systems studied are $\left\{(1-x)\right.$ mol of $C n+x$ mol of $\left.C n^{\prime}\right\}$, such that $n^{\prime}$ is greater than $n: 8$ systems with $\Delta n=\left(n^{\prime}-n\right)=1$, which are $\mathrm{C} 16+\mathrm{C} 17,{ }^{20} \mathrm{C} 17+\mathrm{C} 18,{ }^{22} \mathrm{C} 18+\mathrm{C} 19,{ }^{18} \mathrm{C} 19+\mathrm{C} 20$, $\mathrm{C} 20+\mathrm{C} 21, \mathrm{C} 21+\mathrm{C} 22,{ }^{16} \mathrm{C} 22+\mathrm{C} 23$, and C23 + C24), and 11 with $\Delta \mathrm{n}=2\left(\mathrm{C} 17+\mathrm{C} 19, \mathrm{C} 19+\mathrm{C} 21,{ }^{23} \mathrm{C} 21+\right.$ $\mathrm{C} 23, \mathrm{C} 23+\mathrm{C} 25,{ }^{17} \mathrm{C} 25+\mathrm{C} 27$ and $\mathrm{C} 8+\mathrm{C} 10,{ }^{31} \mathrm{C} 14+$ $\left.\mathrm{C} 16, \mathrm{C} 16+\mathrm{C} 18, \mathrm{C} 18+\mathrm{C} 20, \mathrm{C} 22+\mathrm{C} 24, \mathrm{C} 26+\mathrm{C} 28^{19}\right)$. Their phase diagrams are assembled in Figure $1(\Delta \mathrm{n}=$ 1 , even + odd and odd + even systems), Figure $2(\Delta \mathrm{n}=$ 2 , odd + odd systems), and Figure $3(\Delta n=2$, even + even systems). Each colored zone corresponds to a solid single-phase region: green for $\left[\mathrm{T}_{\mathrm{p}}\right]$, red for $\left[\mathrm{O}_{i}\right]$, pink for $\left[\mathrm{O}_{\mathrm{dci}}\right]$, orange for $\left[\mathrm{O}_{\mathrm{p}}\right]$, blue for $\left[\mathrm{M}_{\mathrm{dci}}\right]$, cyan for $\left[\mathrm{M}_{\mathrm{dcp}}\right]$, violet for [M011], yellow for [RI] and Rv, light yellow for [RII], and green yellow for [RIII] and [RIV]. Mixing leads to the appearance of new phases as $\mathrm{O}_{p}$ and $\mathrm{M}_{\mathrm{dcp}}$ and to the extension of $\mathrm{R}$ phases. The number of solid forms that are stabilized by mixing is relatively high; for example, there are eight solid forms in the C21 + C22 system.

Because the evolution with $\mathrm{n}$ of the structural behavior is quite different for the rotator forms in the HT domain, and the "ordered" forms in the LT domain, we will consider these two domains separately.

New Binary Systems. The systems for which we did not yet publish our experimental results are C19+C20,

(31) Rajabalee, F.; Espeau, P.; Haget, Y.; Cuevas-Diarte, M. A. Mol. Cryst. Liq. Cryst. 1995, 269, 165.
$\mathrm{C} 20+\mathrm{C} 21, \mathrm{C} 21+\mathrm{C} 22, \mathrm{C} 23+\mathrm{C} 24, \mathrm{C} 14+\mathrm{C} 16, \mathrm{C} 16+$ $\mathrm{C} 18, \mathrm{C} 18+\mathrm{C} 20, \mathrm{C} 22+\mathrm{C} 24, \mathrm{C} 17+\mathrm{C} 19, \mathrm{C} 21+\mathrm{C} 23$, and $\mathrm{C} 25+\mathrm{C} 27$. Here, we give a short comment for each of them, comparing our results with those published by other groups.

The $\mathrm{C} 19+\mathrm{C} 20$ phase diagram (Figure 1 ) has been determined by Mazee. ${ }^{32} \mathrm{H}$ is solid-liquid loop and the dimensions of the HT domain are in agreement with our result. Mazee's loop for the transition from the LT to the HT domain is based on the (false) assumption that C19 and C20 are isomorphous at LT, yielding a continuous series of mixed crystals. Today, we know that C19 is orthorhombic and C20 is triclinic; in addition, we have identified the three intermediate phases $\mathrm{O}_{\mathrm{dc}}, \mathrm{M}_{\mathrm{dc}}$, and $\mathrm{O}_{\mathrm{p}}$. The $\mathrm{C} 19+\mathrm{C} 20$ phase diagram is very similar to the $\mathrm{C} 17+\mathrm{C} 18$ diagram, ${ }^{22}$ except for the appearance of the narrow $\left[\mathrm{O}_{\mathrm{dci}}\right]$ single-phase region.

The C20 + C21 phase diagram (Figure 1) is very similar to the one for $\mathrm{C} 18+\mathrm{C} 19 ;{ }^{18}$ the $[\mathrm{RI}]$ single-phase region of the latter is larger.

The $\mathrm{C} 22+\mathrm{C} 23$ diagram (Figure 1 ) is in agreement with the diagram proposed by Nouar et al. ${ }^{7}$ some small differences should be noticed, however. In agreement with Sirota, ${ }^{27}$ we concluded that C22 presents the RI phase and we observed total miscibility in this phase. The minimum in the $\left[R_{I}+R_{I I}\right]$ loop is situated around $x=0.25$, as in the other systems (N ouar's minimum is close to $x=0.50$ ). For the $\Phi_{\text {ord }} \rightarrow \mathrm{R}$ equilibria, Nouar proposed a loop with a maximum for the $O_{p} \rightarrow R$ transition, giving rise to two eutectoïd $\left[T_{p}+O_{p}+R\right]$ and $\left[\mathrm{O}_{p}+\mathrm{M}_{\mathrm{dci}}+\mathrm{R}\right]$ equilibria. We established, just as for the other even + odd systems (see Figure 1 ), that the two three-phase equilibria are peritectoïd and eutectoïd, respectively. Another discrepancy concerns the nature of intermediate $\Phi_{\text {ord }}$ phases. The intermediate phases reported by Nouar are $\gamma_{0}, \beta_{1}^{\prime}, \beta_{1}^{\prime \prime}, \beta_{0}^{\prime}$, and $\beta_{0}$; they correspond to $\mathrm{T}_{\mathrm{p}}, \mathrm{O}_{\mathrm{p}}, \mathrm{M}_{\mathrm{dc}}, \mathrm{O}_{\mathrm{dc}}$, and $\mathrm{O}_{i}$, respectively. Whereas Nouar indicated that they all are orthorhombic, we established that one of them $\left(\beta_{1}^{\prime}\right)$ is the $M_{\mathrm{dci}}$

(32) Mazee, W. M. Anal. Chim. Acta 1957, 17, 1, 97. 

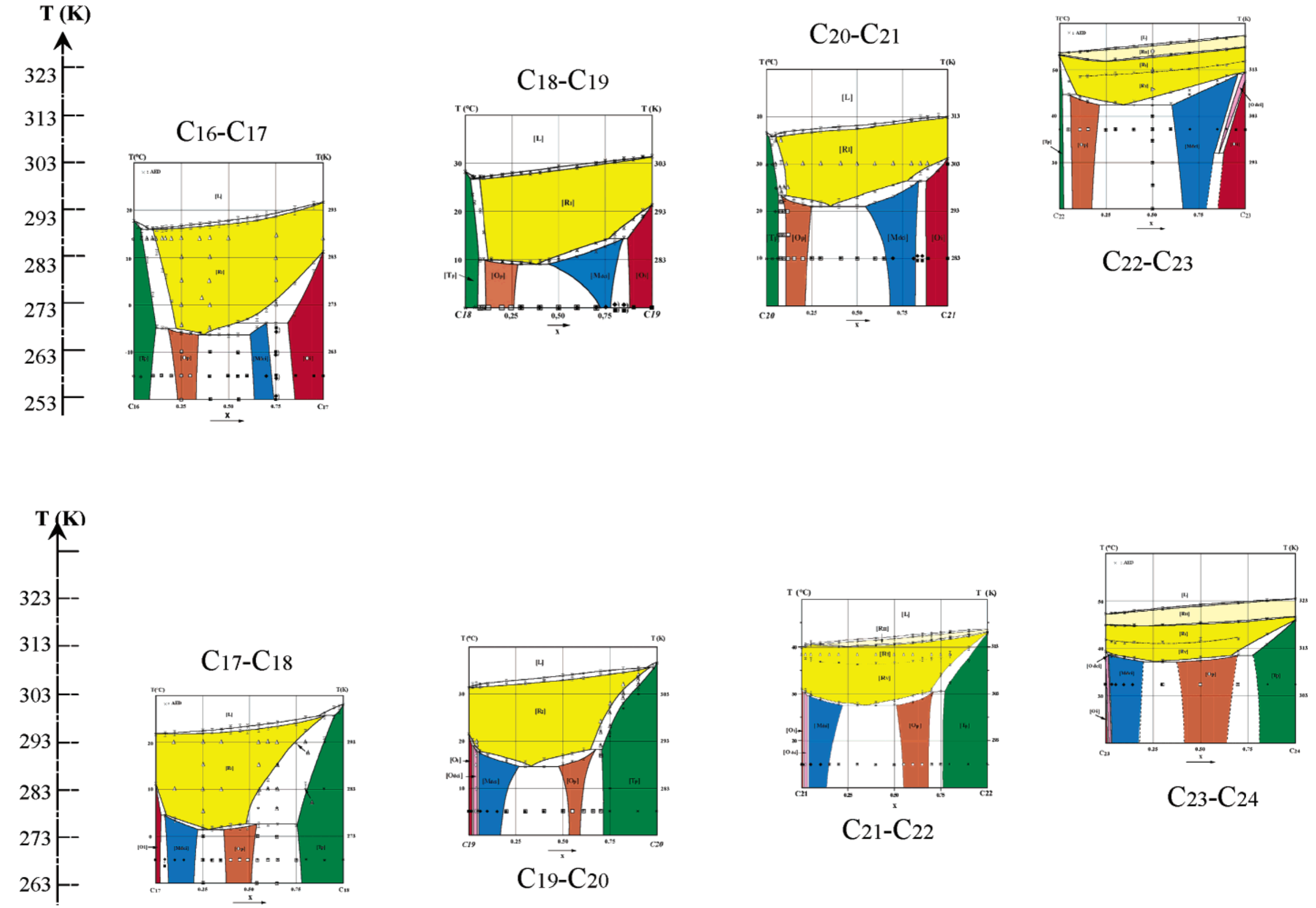

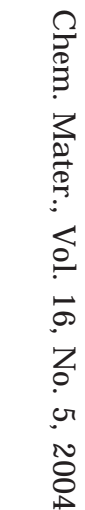

Figure 1. Binary phase diagrams: even + odd and odd + even systems $(\Delta n=1)$. Solid single-phase regions: green for $\left[T_{p}\right]$, red for $\left[\mathrm{O}_{i}\right]$, pink for $\left[\mathrm{O}_{d c}\right]$, orange for $\left[\mathrm{O}_{p}\right]$, blue for $\left[\mathrm{M}_{d c}\right]$, yellow for $[\mathrm{RI}]$ and $[\mathrm{Rv}]$, and light yellow for $[\mathrm{R} ॥]$.

\section{$\mathrm{C}_{21-\mathrm{C} 22}$}

$\mathrm{C} 23-\mathrm{C} 24$ 

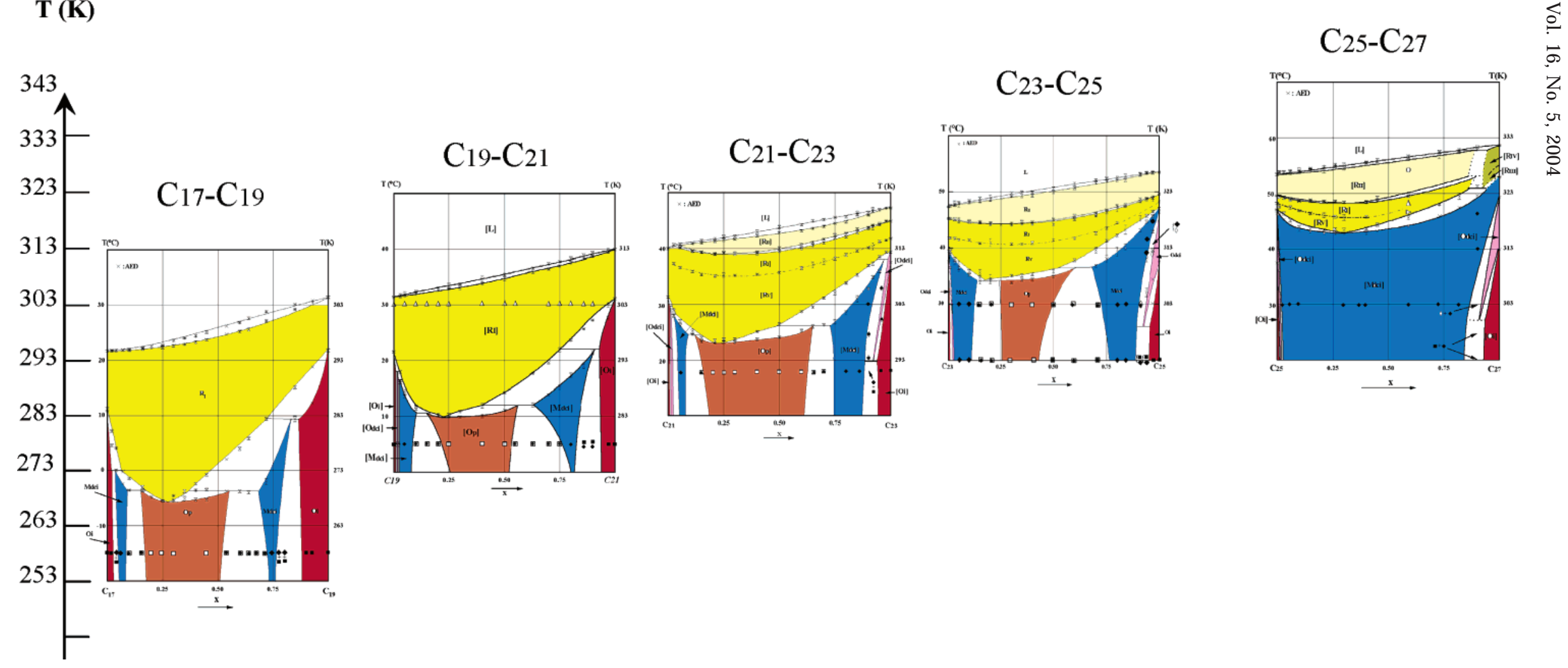

Figure 2. Binary phase diagrams: odd + odd systems $(\Delta n=2)$. Solid singlephase regions: green for $\left[T_{p}\right]$, red for $\left[\mathrm{O}_{\mathrm{i}}\right]$, pink for $\left[\mathrm{O}_{d c i}\right]$, orange for $\left[\mathrm{O}_{p}\right]$, blue for $\left[\mathrm{M}_{d c}\right]$, violet for $[M 011]$, yellow for $[R I]$ and $[R v]$, light yellow for [RII], and green yellow for [RıI] and [RIV]. 


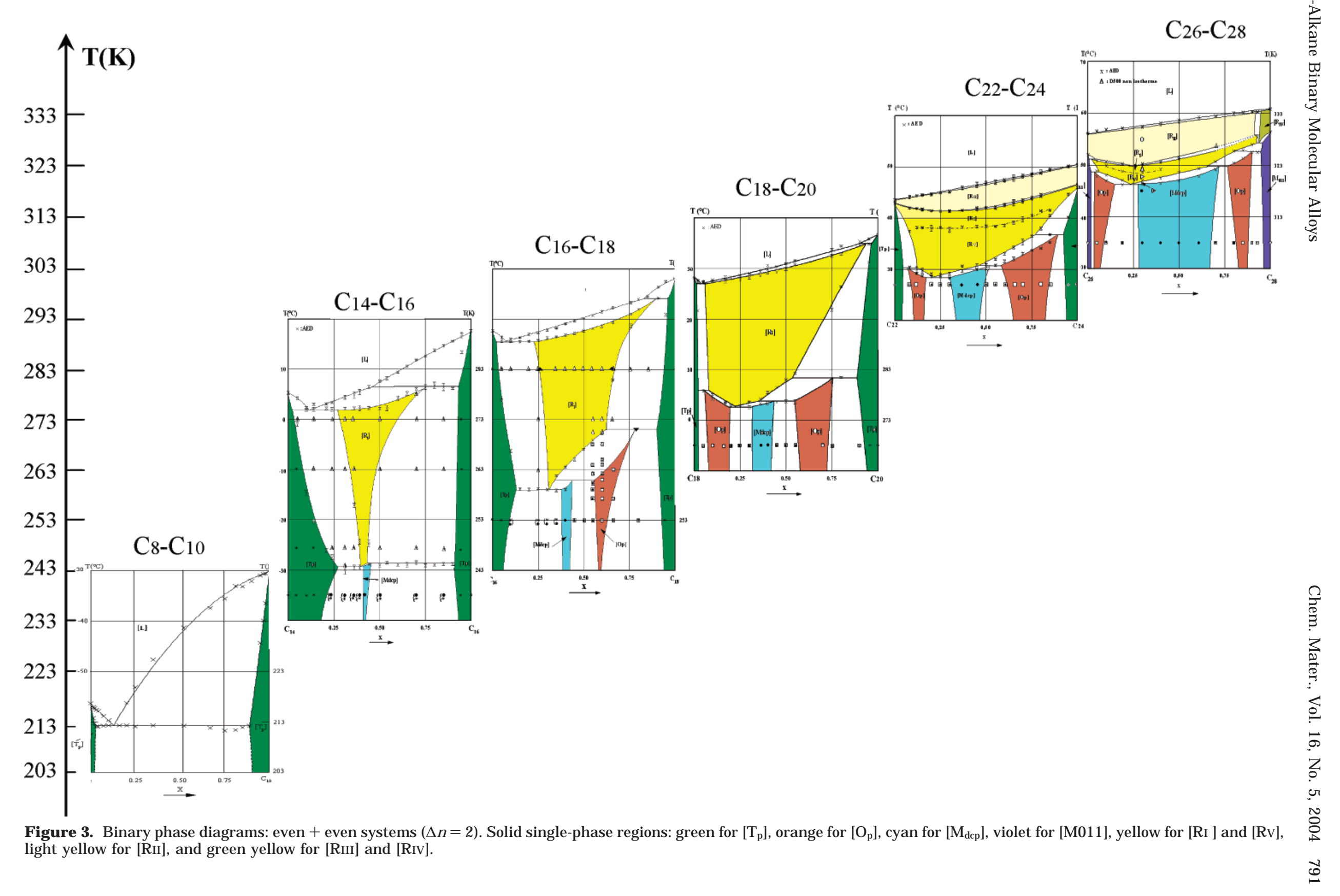


monoclinic phase (this was confirmed by our study of the $\mathrm{C} 23+\mathrm{C} 25^{17}$ and $\mathrm{C} 25+\mathrm{C} 27$ systems, where $\mathrm{M}_{\mathrm{dci}}$ is stable for C25 and C27).

The C23 + C24 system (Figure 1 ) has also been studied by Nouar et al. ${ }^{8}$ Their phase diagram and ours are fairly similar; two differences can be noticed, however. The first is related to the $[R I+R I I]$ equilibrium. In agreement with Sirota, ${ }^{27}$ we confirmed that RI is stable for C24; as a consequence, we observed total miscibility for RI, the [RI + RII] two-phase region being a single loop. Nouar, on the other hand, proposed an $\left[R I+R I I+T_{p}\right]$ peritectoïd equilibrium. The second difference concerns the nature of the intermediate $\left(\beta_{1}^{\prime \prime}\right)$ $\Phi_{\text {ord }}$ phase; see above for C22 + C23.

As far as we know, the $\mathrm{C} 17+\mathrm{C} 19$ phase diagram was only published by Robles et al. ${ }^{33}$ At that time, we indicated total miscibility between the two components, in the $\Phi_{\text {ord }}$ phase $O_{i}$ as well as in Rı. By means of the analysis of X-ray reflections with large angles we have identified three intermediate single-phase regions: the $\left[\mathrm{O}_{p}\right]$ single-phase region in the central part of the phase diagram is surrounded by two narrow $\left[\mathrm{M}_{\mathrm{dc}}\right]$ regions; the revised phase diagram is shown in Figure 2. The $\Phi_{\text {ord }} \rightarrow$ Rı transition has four peritectoïd equilibria and a minimum in the $\left[\mathrm{O}_{p}+\mathrm{R}_{1}\right]$ loop.

The C21 + C23 system (Figure 2) previously has been studied by J outi et al.; 34 their phase diagram is in fair agreement with our results. Four differences may be mentioned: (i) we detected the second-order Rv $--\rightarrow$ $\mathrm{R}$ । transition at a higher position; (ii) their $\left[\mathrm{O}_{p}\right]$ intermediate single-phase region is slightly wider; (iii) al though the number of intermediate $\Phi_{\text {ord }}$ single-phase regions is the same, J outi found four intermediate $\Phi_{\text {ord }}$ phases $\left(\beta_{0}^{\prime}, \beta_{1}^{\prime \prime}, \beta_{1}^{\prime}\right.$, and $\left.\beta_{2}^{\prime}\right)$, whereas we established that there are only three $\left(\mathrm{O}_{\mathrm{dc}}, \mathrm{M}_{\mathrm{dci}}\right.$, and $\mathrm{O}_{\mathrm{p}}$; the $\mathrm{M}_{\mathrm{dci}}$ phase is located in two fields separated by the $\mathrm{O}_{p}$ single-phase region); (iv) we found that the $\left[\mathrm{O}_{p}+\mathrm{Rv}\right]$ two-phase region has a minimum close to $x=0.25$ (just as for the $\mathrm{C} 17+\mathrm{C} 19$ and $\mathrm{C} 19+\mathrm{C} 21$ systems) and that the $\left[\mathrm{O}_{\mathrm{p}}+\right.$ $\mathrm{M}_{\mathrm{dci}}+\mathrm{Rv}$ ] equilibria are peritectoïd; J outi, on the other hand, proposed a eutectoïd and a peritectoïd equilibrium.

As far as we know, the C25 + C27 binary phase diagram (Figure 2) has not yet been published. Pure C25 and C27 have the same sequence of phases at low temperature $\left(\mathrm{O}_{\mathrm{i}} \rightarrow \mathrm{O}_{\text {dci }} \rightarrow \mathrm{M}_{\text {di }}\right)$ but different rotator phases before melting. The phase diagram has five single-phase regions in the LT domain, involving three phases $\left(\mathrm{O}_{i}, \mathrm{O}_{d c}\right.$, and $\left.\mathrm{M}_{\mathrm{dc}}\right)$; no intermediate $\mathrm{O}_{\mathrm{p}}$ phase has been detected, in contrast with the other odd + odd systems. We established that, below the $\Phi_{\text {ord }} \rightarrow \mathrm{R}$ transition, there is a continuous series of mixed crystals of the $M_{d c i}$ type. At room temperature the large $M_{d c i}$ single-phase region is enclosed by a very narrow $\mathrm{O}_{\mathrm{dci}}$ one and another one, $\mathrm{O}_{i}$, at the $\mathrm{C} 25$ and C27 sides, respectively. The $M_{d c i} \rightarrow R$ transition has a $\left[M_{d c i}+R v\right.$ ] loop with a minimum close to $x=0.25$ and a eutectoid $\left[\mathrm{M}_{\mathrm{dci}}+\mathrm{Rv}+\mathrm{RIII}\right]$, situated near C27. The RI $\rightarrow$ RII loop is very narrow (as in all the other systems), and the [RI + RII + RIII] equilibrium is a peritectoïd near C27. The

(33) Robles, L.; Espeau, P.; Mondieig, D.; Haget, Y.; Oonk, H. A.J . Thermochim. Acta 1995, 2422, 1.

(34) J outi, B.; Provost, E.; Petitjean, D.; Bouroukba, M.; Dirand, M. J . Mol. Struct. 1996, 49. two melting loops, $\mathrm{R} \| \mathrm{L}$ and $\mathrm{Rv} \rightarrow \mathrm{L}$, are separated by a $[\mathrm{L}+\mathrm{R} I \mathrm{I}+\mathrm{RV}]$ peritectic equilibrium.

The two components of the $\mathrm{C} 14+\mathrm{C} 16$ system are triclinic. The phase diagram (Figure 3 ) has four singlephase regions and two intermediate phases for central compositions: $\left[M_{d c p}\right]$ in the $L T$ domain and $\left[R_{I}\right]$ in the HT domain. The single-phase regions are rather narrow. At LT, there are two $\left[T_{p}+M_{d c i}+R_{I}\right]$ three-phase equilibra: a eutectoïd at the $\mathrm{C} 14$ side (between $\mathrm{x} \approx 0.25$ and $x \approx 0.41$ ) and a very large peritectoïd from $x \approx 0.43$ up to $x \approx 0.90$. At HT, there are a eutectic three-phase equilibrium, from $x=0.09$ up to $x=0.30$, and a perictectic one, from $x=0.46$ up to $x=0.93$.

The C16 + C18 phase diagram (Figure 3 ) has been studied previously by Mazee. ${ }^{32}$ Mazee's diagram is in agreement with our result, as far as the HT domain is concerned (in particular, the fact that the intermediate Rı phase is observed in a large area). There are, however, some differences: in Mazee's phase diagram the solid-liquid three-phase equilibria are narrower than those in our proposition; and for the $[R+L]$ twophase region Mazee proposed a loop with a minimum. With regard to the LT domain, Mazee's diagram displays a continuous series of mixed crystals, against the two intermediate phases, $M_{d c p}$ and $O p$, in our diagram. The $\left[T_{p}+M_{d c p}+R_{l}\right]$ three-phase equilibrium is a eutectoid; $\left[\mathrm{O}_{p}+\mathrm{M}_{\mathrm{dcp}}+\mathrm{RI}_{\mathrm{I}}\right]$ and $\left[\mathrm{O}_{\mathrm{p}}+\mathrm{T}_{\mathrm{p}}+\mathrm{RI}_{\mathrm{I}}\right]$ are peritectoïd.

Similarly, for the C18 + C20 system, our diagram, Figure 3, is in agreement with Mazee ${ }^{35}$ in the HT domain and in disagreement in the LT domain, where again he assumed the existence of a continuous series of mixed crystals. In the HT domain, the [RI] region is wider than that in $\mathrm{C} 16+\mathrm{C} 18$, and melting occurs in a very narrow temperature range (less than $2 \mathrm{~K}$ ). In the $\mathrm{LT}$ domain, there are five single-phase regions, which are $\left[T_{p}\right],\left[O_{p}\right],\left[M_{d c p}\right],\left[O_{p}\right]$, and $\left[T_{p}\right]$; the regions of the intermediate phases are larger than those in the C16 + C18 system. The two $\left[T_{p}+O_{p}+R_{1}\right]$ equilibria are peritectoïd, and the $\left[O_{p}+M_{d c p}+R_{I}\right]$ equilibrium is eutectoild at the C18 side and peritectoid at the C20 side.

The C22 + C24 has been studied by a number of research groups, in particular, by Dirand et al. (with references to earlier work). ${ }^{36}$ Although our phase diagram (Figure 3) is in fair agreement with Dirand's proposition (agreement: RII continuous series of solid solutions; same number of $\Phi_{\text {ord }}$ regions), some differences should be noted. In the HT domain, Dirand observed Rı only in mixed samples and not for the components (see above); as a consequence, he proposed two pertectoid $\left[R ı+R ı+T_{p}\right]$ equilibria, against a continuous series of RI mixed crystals in our diagram. In the LT domain, there is a difference with regard to the nature of one of the phases. We found that the X-ray patterns of the phase located in the middle of the diagram ( $\left(\mathrm{M}_{\mathrm{dcp}}\right.$, called $\beta{ }_{1}{ }_{1}$ by Dirand) can be indexed in the monoclinic space group $\mathrm{Aa}$, whereas Dirand indicated that all the intermediate $\Phi_{\text {ord }}$ phases are orthorhombic. In addition, we found that, apart from $M_{d c p}$, there are two $\mathrm{O}_{p}$ single-phase regions, whereas Dirand

(35) Mazee, W. M. Am. Chem. Div. Pet. Chem. 1958, 3, 4 B-35.

(36) Dirand, M.; Achour, Z.; J outi, B.; Sabour, A.; Gachon J . C. Mol Cryst. 1996, 275, 293. 
indicated the existence of two intermediate phases named $\beta_{1}^{\prime}$ and $\beta_{2}^{\prime}$.

Comments on the High-TemperatureDomains for the Set of Binaries. The most striking aspect of the binary systems is that the rotator form is stabilized by mixing: not only that the rotator single-phase regions are much wider than those for the triclinic form, the rotator form is even present in systems where it does not appear for the pure components.

(i) RI is observed in all binary systems except for C8 + C10 (which has a large eutectic between the triclinic forms). When Rı is displayed by the two components, there is total miscibility.

(ii) Rv and Rı are present for systems with $22 \leq \mathrm{n} \leq$ 25 , and it is RII which melts; there is total miscibility (see Figures 1, 2, and 3 for C22 + C23, C23 + C24, C23 $+\mathrm{C} 25$, and C22 + C24; and C24 + C26 by AchourBoudjema al. $\left.{ }^{9}\right)$. In C21 + C22 either RII or Rı mixed crystals are the ones that melt and in C26 + C2819 either RII or RIV (contrary to what is proposed by Prevot, ${ }^{37}$ who mentioned total miscibility in Rı); the largest region before melting is for R॥.

Four different types of phase-transition sequences take place in the HT domain: $\mathrm{T}_{\mathrm{p}} \rightarrow$ Liquid, $\mathrm{R} \mathrm{I} \rightarrow$ Liquid, $\mathrm{RV}--\rightarrow \mathrm{RI} \rightarrow \mathrm{RII} \rightarrow$ Liquid or RIV $--\rightarrow$ RIII $\rightarrow$ Liquid. The Rv -- $\rightarrow$ RI transition appears in the C21 + C22 system even though Rv is not stable for pure C21 and C22 (in fact, metastable Rv appears when C22 is cool ed from the liquid ${ }^{27}$ ). It can be noticed that the Rv form is observed over a wide range of compositions in all of the systems that display Rı.

Complete miscibility in $\mathrm{R}$ forms is observed when the two components are isomorphous. The temperature ranges of the rotator forms are much larger in mixed samples than for the pure components (the maximum extent is around $x=0.30$ ). For example, $R I$ is observed over $10.3 \mathrm{~K}$ for $\mathrm{C} 17$ while it is stabilized over 22.5 and $19.8 \mathrm{~K}$ for the mixed samples in $\mathrm{C} 16+\mathrm{C} 17$ and $\mathrm{C} 17+$ C18, respectively. In Figure 4, we have plotted the temperature extent $(\Delta T)$ of the total rotator domain (the full HT domain); for the pure alkanes as a function of $n$ (- for $\Delta \mathrm{n}=0)$, and for the $\mathrm{Cn}+\mathrm{Cn}^{\prime}$ systems as a function of $\bar{n}=x_{m} \cdot n^{\prime}+\left(1-x_{m}\right) \cdot n(\square$ [red box] for $\Delta n$ $=1$ and $\bullet$ [blue tilted square] for $\Delta n=2$ ), where $x_{m}$ is the composition at which the $\Phi_{\text {ord }}$ to $R$ transition has the lowest temperature. $\Delta \mathrm{T}$ increases with $\Delta \mathrm{n}$ (in agreement with Sirota: 38 the range of stability of the rotator phases is enhanced by increasing the width of distribution of the n-alkanes) and decreases steeply with increasing chain length, in the sense that from C 39 on, the rotator forms are no longer observed. A reason could be that intramolecular kink defects (of which the concentration increases with chain length) would act as a brake for the free rotation of the molecules.

Comments on the Low-Temperature Domains for the Set of Binaries. In most of the systems, additional $\Phi_{\text {ord }}$ phases (not stable for the pure components) are stabilized. We have identified all the additional phases; most of them correspond to forms that are stable for longer al kanes (longer than the components of the system). In

(37) Provost, E.; Balesdent, D.; Bouroukba, M.; Petitjean, D.; Dirand, M.; Ruffier-Meray, V. J. Chem. Thermodyn. 1999, 31, 1135. (38) Sirota, E. B.; King, H. E.; Shao, H. H.; Singer, D. M J . Chem. Phys. 1995, 99, 798.

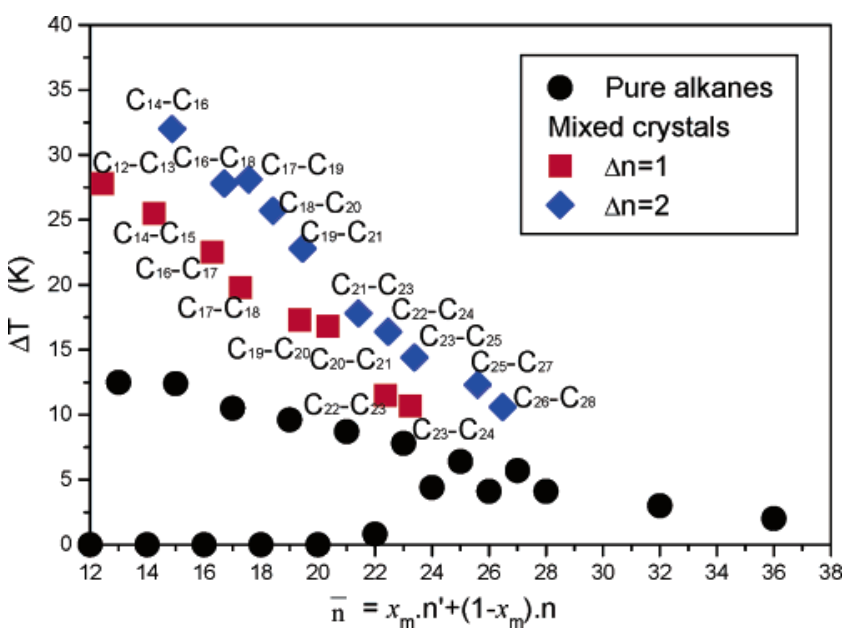

Figure 4. Temperature range $(\Delta T)$ of the full rotator domains for the pure alkanes as a function of $n(-$ for $\Delta n=0)$ and for all the $\mathrm{Cn}-\mathrm{Cn}^{\prime}$ systems ( $\Delta \mathrm{T}$ has been measured at the composition $x_{m}$ where the $\Phi_{\text {ord }} \rightarrow R$ transition temperature is at its minimum) as a function of $\bar{n}=x_{m} \cdot n^{\prime}+\left(1-x_{m}\right) \cdot n^{\prime}(\square$ for $\Delta \mathrm{n}=1$ and $\diamond$ for $\Delta \mathrm{n}=2$ ).

Table 3. Sequences of the $\Phi_{\text {ord }}$ Single-Phase Regions on the Composition Scale

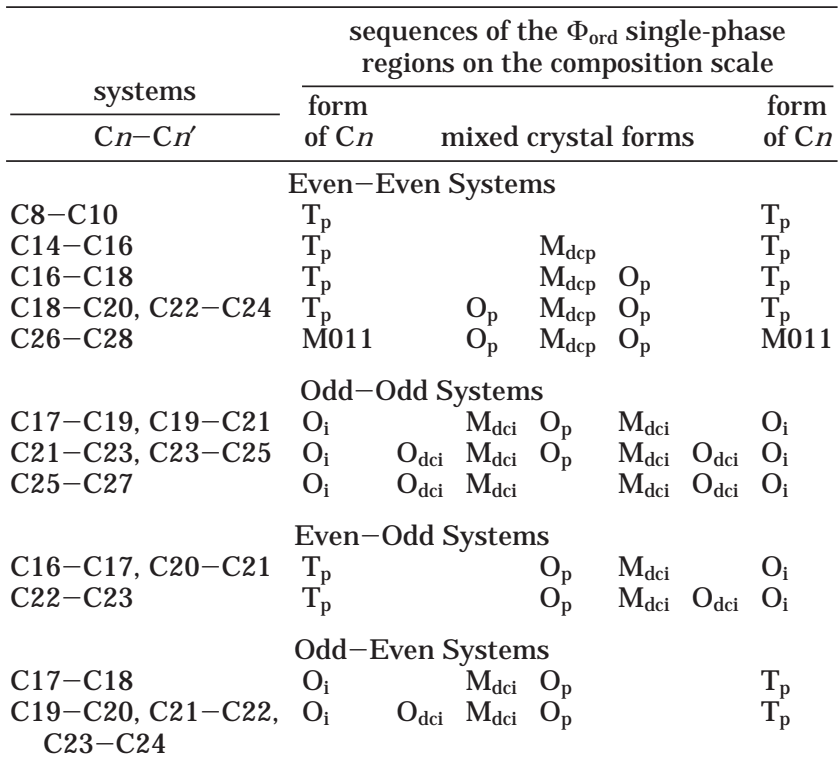

the range of alkanes studied, seven "ordered" forms are observed: $T_{p}, M 011, O_{i}, O_{d c i}, M_{d c i}, M_{d c p}$, and $O_{p}$. The $O_{p}$ form is orthorhombic $\left(\mathrm{Pca}_{1}, \mathrm{Z}=4^{39}\right)$ and it is observed as a metatsable form in even alkanes with $n \geq 28$. $^{19,40}$ The $M_{d c p}$ phase is observed only in even + even systems. The curve of the $\mathrm{M}_{\mathrm{dcp}} \rightarrow \mathrm{R}$ transition temperature as a function of $n$ is slightly below the $M_{d c i} \rightarrow R$ one. The X-ray diffraction patterns of $\mathrm{M}_{\mathrm{dcp}}$ and $\mathrm{M}_{\mathrm{dci}}$ are similar: the two can be indexed in the same space group, which is $\mathrm{Aa}$. The space groups of the other phases are given in Table 1 . The sequences of the $\Phi_{\text {ord }}$ single-phase regions in terms of composition are presented in Table 3. The number of additional single-phase regions reaches 3 in the $\Delta n=1$ systems and in the even + even systems;

(39) Teare, P. W. Acta Crystallogr. 1959, 12, 294.

(40) Poirier, B. Ph.D. Thesis, University of Bordeaux I, 1996. 
in odd + odd systems it varies from 3 to 5 . For $\Delta n=2$, the longest sequences of single-phase regions are as follows:

for even + even systems:

$$
\mathrm{T}_{\mathrm{p}} \text { (or } \mathrm{M} 011 \text { ) } / \mathrm{O}_{\mathrm{p}} / \mathrm{M}_{\mathrm{dcp}} / \mathrm{O}_{\mathrm{p}} / \mathrm{T}_{\mathrm{p}} \text { (or M 011) }
$$

for odd + odd systems:

$$
\mathrm{O}_{\mathrm{i}} / \mathrm{O}_{\mathrm{dci}} / \mathrm{M}_{\mathrm{dci}} / \mathrm{O}_{\mathrm{p}} / \mathrm{M}_{\mathrm{dci}} / \mathrm{O}_{\mathrm{dci}} / \mathrm{O}_{\mathrm{i}}
$$

These sequences can be qualified as symmetrical. For the $\Delta \mathrm{n}=1$ systems, the longest sequence can be divided into two parts: one $\left(\mathrm{O}_{\mathrm{i}} / \mathrm{O}_{\mathrm{dc}} / \mathrm{M}_{\mathrm{dc}}\right.$; similar to one-half of the odd + odd sequence), near the odd component, and the other $\left(T_{p} / \mathrm{O}_{p}\right.$; similar to one-half of the even + even sequence) near the even component. Passing over the difference in point of view, with regard to the nature of the phases, the longest sequences are in agreement with the rule proposed by Dirand. ${ }^{15}$ I $\mathrm{n}$ fact, in the range from $\mathrm{n}=8$ to $\mathrm{n}=28$, the longest sequences are observed only for the longer alkane systems; for shorter alkanes the number of single-phase regions is lower.

With regard to the occurrence of a continuous series of mixed crystals-which is a possibility when the two components of the system are isomorphous-the only example observed is $\mathrm{M}_{\text {dci }}$ in $\mathrm{C} 25+\mathrm{C} 27$.

To compare their extents (in terms of composition), the widths of the single-phase regions were measuredfor conditions just below the lower solvus of the $\left[\Phi_{\text {ord }}+\right.$ $\mathrm{R}]$ two-phase region. In this respect two groups of phases can be distinguished: the phases $\mathrm{T}_{\mathrm{p}}, \mathrm{M} 011, \mathrm{O}_{\mathrm{i}}$, and $\mathrm{O}_{\mathrm{dci}}$, which are located near the pure components, with narrow regi ons, and the central phases $M_{d c p}, M_{d c i}$, and $\mathrm{O}_{\mathrm{p}}$ with wider regions. In detail,

(i) $T_{p}$ alloys, close to even alkanes, have widths that never exceed $25 \%$. The general trend is a decrease of width with increasing chain length (see Figures 1 and 3).

(ii) $\mathrm{O}_{i}$ alloys, just as $\mathrm{T}_{p}$ alloys, only exist in binaries where the form is stable for the pure components. The extent in composition of the $\mathrm{O}_{i}$ domain does not exceed $20 \%$ and it decreases with chain length.

(iii) $\mathrm{O}_{\text {di }}$ regions are very narrow (less than $3 \%$ ). In addition to systems involving C23, C25, and C27 (in which, for the pure alkane, $\mathrm{O}_{\mathrm{dci}}$ is stable), $\mathrm{O}_{\mathrm{dci}}$ regions also appear in binaries involving odd alkanes (from $n$ $=19$ on) where the odd alkane is the shorter one (for instance, the form is stabilized in C21 + C22 but not in C20 + C21 and in C19 + C21 it appears only at the C19 side).

(iv) $M_{d c p}$ and $M_{d c i}$ have single-phase regions that become wider with increasing $n$. $M_{d c p}$ regions are situated in the center of even + even binaries; the $M_{d c i}$ ones are situated close to $\mathrm{O}_{\mathrm{dci}}$ (or $\mathrm{O}_{i}$ when there is no $\mathrm{O}_{\text {dci }}$ domain) in odd + odd systems, and also in systems with $\Delta \mathrm{n}=1$.

(v) $\mathrm{O}_{\mathrm{p}}$ mixed crystals are stabilized in all of the $\Delta \mathrm{n}=$ 1 systems and in nearly all $\Delta \mathrm{n}=2$ systems. They are located near the even alkane and for odd + odd systems in the center (between $M_{\text {di }}$ domains). The width of the $\mathrm{O}_{\mathrm{p}}$ region reaches $45 \%$ (for $\mathrm{C} 21+\mathrm{C} 23$ ). For $\Delta \mathrm{n}=2$ systems, it increases and then decreases with $\mathrm{n}$ (there is no $\mathrm{O}_{\mathrm{p}}$ region in $\mathrm{C} 25+\mathrm{C} 27$ ).
A general trend of the $\Phi_{\text {ord }}$ single-phase regions is that they are wider near the longer component, and such that the solubility of the shorter alkane in the longer one is higher than the solubility of the longer in the shorter one.

(b) Lattice Parameters of the Ordered Mixed Crystals. From X-ray powder diffraction data we have determined the cell parameters of numerous compositions of $M_{d c i}, M_{d c p}$, and $O_{p}$ mixed crystals, using the "pattern-matching" option of the program FULLPROF. 41 In Table 4, are given the lattice parameters (uncertainties are inferior or equal to $0.04 \AA$ for $a$ and $b$; to $0.04^{\circ}$ for $\beta$; and to $0.09 \AA$ for $\mathrm{c}$ ), the volume, the specific volume, and the temperature at which they were determined. Figure 5a shows the volumes of mixed crystals $\left(\mathrm{M}_{\mathrm{dc}}, \mathrm{M}_{\mathrm{dcp}}, \mathrm{O}_{\mathrm{dci}}\right.$, and $\left.\mathrm{O}_{\mathrm{p}}\right)$ and pure alkanes $\left(\mathrm{O}_{\mathrm{i}}\right.$ for all values of $n ; O_{\text {dci }}$ for $n=23,25$, and 27 and $M_{\text {dci }}$ for $n=$ 25 and 27) as a function of $n_{x}$ (for an alloy $A_{1-x} B_{x}: n_{x}=$ $\left.\mathrm{x} \cdot \mathrm{n}_{\mathrm{B}}+(1-\mathrm{x}) \cdot \mathrm{n}_{\mathrm{A}}\right)$. The data corresponding to $\Delta \mathrm{n}=1$ and $\Delta \mathrm{n}=2$ are distinguished by the symbols " $\mathrm{x}$ " and "o" respectively. It appears, in a clear manner, that the volumes of mixed crystals are somewhat greater than the ones of the pure components (a linear fit of the $\mathrm{O}_{i}$ data for pure components leads to the relationship $\mathrm{V}_{\mathrm{O}_{i}}$ $\left(\AA^{3}\right)=126.5+94.856 \cdot n_{x}$, with a reliability factor $R=$ 0.9997); this is mainly due to an increase of the interlayer distance $c \sin \beta$ (Figure $5 c$; a linear fit of the $\mathrm{O}_{i}$ data for pure components leads to the following relationship $c(\AA)=3.89+2.535 \cdot n_{x}$ with $\left.R=0.9999\right)$ and an increase of the a parameter (Figure $5 \mathrm{~b}$ ). There is no clear distinction between the $\Delta \mathrm{n}=1$ and $\Delta \mathrm{n}=2$ systems.

(c) Solid-Liquid and Solid-Solid Equilibria. Within the range $n=8$ to $n=28$ four types of solidliquid equilibrium can be distinguished:

(i) $\left[T_{p}+L\right.$ ] two-phase regions are always situated close to the even component (for $n<22$ ); their $x$-range is small. When they interfere with the $[\mathrm{RI}]$ region, they give rise to eutectic and peritectic three-phase equilibria near the shorter and longer component, respectively. In the case of $\mathrm{C} 8+\mathrm{C} 10$, where Rı mixed crystals are absent, there is only a eutectic three-phase equilibrium.

(ii) $[R I+L]$ two-phase regions (for $n<22$ ) are narrow in terms of temperature, generally $\leq 2 \mathrm{~K}$ (the largest temperature ranges are for the short-chain even + even systems, but $\Delta T$ remains $\leq 6 \mathrm{~K}$ ).

(iii) $[\mathrm{R} I I+L$ ] two-phase regions are wide in composition and very narrow in temperature $(\leq 2 \mathrm{~K})$.

(iv) [RIV + L] two-phase regions (in C25 + C27 and $\mathrm{C} 26+\mathrm{C} 28$ ) have a limited range in composition and are narrow in temperature.

The solid-solid [RI + RII] region is, in all of the phase diagrams, a very narrow loop, with a minimum around $\mathrm{x}=0.25$.

Among the solid-solid $\left[\Phi_{\text {ord }}+\mathrm{RI}\right]$ equilibria, $\left[\mathrm{O}_{i}+\right.$ $\mathrm{RI}_{\mathrm{I}}$, $\left[\mathrm{O}_{\mathrm{dci}}+\mathrm{RI}_{\mathrm{I}}\right]$, and $\left[\mathrm{T}_{\mathrm{p}}+\mathrm{RI}_{\mathrm{I}}\right]$ have steep boundaries. The boundaries of $\left[\mathrm{O}_{\mathrm{p}}+\mathrm{RI}_{\mathrm{I}}\right],\left[\mathrm{M}_{\mathrm{dcp}}+\mathrm{RI}\right]$, and $\left[\mathrm{M}_{\mathrm{dci}}+\right.$ $\mathrm{RI}$ ] are less steep; the regions are parts of flat loopswith or without a minimum. These loops are wider at the side of the longer alkane than at the side of the shorter alkane.

(41) Rodriguez-Carvajal, J. FULLPROF, a program for Rietveld refinement and pattern matching analyses: Abstracts of the satellite meeting on powder diffraction of the XV th congress of the International Union of Crystallography, Toulouse, France, 1990; p 11. 
Table 4. Lattice Parameters of $A_{1-x} B_{x}$ Mixed Crystals and Pure Components ${ }^{a}$

\begin{tabular}{|c|c|c|c|c|c|c|c|c|c|c|c|}
\hline $\mathrm{n}_{\mathrm{A}}$ & $\mathrm{n}_{\mathrm{B}}$ & $x$ & $\mathrm{n}_{\mathrm{x}}$ & $\mathrm{a}(\AA)$ & $b(\AA)$ & $c(\AA)$ & $\beta$ (deg) & $c \sin \beta(\AA)$ & $V\left(\AA^{3}\right)$ & $\mathrm{v}\left(\mathrm{cm}^{3} \cdot \mathrm{g}^{-1}\right)$ & $\mathrm{T}(\mathrm{K})$ \\
\hline \multicolumn{12}{|c|}{$M_{\text {dci }}$ Alloys Aa, $Z=4$} \\
\hline 16 & 17 & 0.70 & 16.7 & 7.43 & 5.01 & 46.59 & 92.4 & 46.55 & 1733 & 1.106 & 258 \\
\hline 17 & 19 & 0.05 & 17.1 & 7.45 & 5.01 & 47.54 & 91.2 & 47.53 & 1774 & 1.106 & 258 \\
\hline 17 & 18 & 0.15 & 17.15 & 7.48 & 5.02 & 47.55 & 92.2 & 47.52 & 1784 & 1.109 & 268 \\
\hline 17 & 19 & 0.75 & 18.5 & 7.45 & 5.02 & 51.76 & 92.3 & 51.72 & 1934 & 1.115 & 258 \\
\hline 18 & 19 & 0.75 & 18.75 & 7.45 & 5.01 & 51.35 & 91.9 & 51.32 & 1916 & 1.090 & 273 \\
\hline 19 & 20 & 0.10 & 19.1 & 7.45 & 5.00 & 52.49 & 91.9 & 52.46 & 1954 & 1.092 & 278 \\
\hline 19 & 21 & 0.05 & 19.1 & 7.47 & 5.02 & 52.72 & 91.6 & 52.70 & 1976 & 1.104 & 278 \\
\hline 19 & 21 & 0.80 & 20.6 & 7.46 & 5.01 & 56.98 & 92.7 & 56.92 & 2127 & 1.102 & 278 \\
\hline 20 & 21 & 0.70 & 20.7 & 7.49 & 5.01 & 57.08 & 91.7 & 57.05 & 2141 & 1.104 & 283 \\
\hline 21 & 22 & 0.05 & 21.05 & 7.51 & 4.99 & 57.42 & 91.3 & 57.40 & 2151 & 1.091 & 288 \\
\hline 21 & 23 & 0.054 & 21.11 & 7.50 & 5.02 & 57.71 & 91.0 & 57.70 & 2172 & 1.099 & 290 \\
\hline 21 & 23 & 0.80 & 22.6 & 7.51 & 5.01 & 62.23 & 91.5 & 62.21 & 2341 & 1.106 & 290 \\
\hline 22 & 23 & 0.85 & 22.85 & 7.54 & 5.02 & 62.59 & 91.6 & 62.57 & 2368 & 1.107 & 300 \\
\hline 23 & 24 & 0.05 & 23.05 & 7.52 & 5.02 & 62.96 & 93.2 & 62.86 & 2373 & 1.010 & 300 \\
\hline 23 & 25 & 0.05 & 23.1 & 7.49 & 5.00 & 62.63 & 91.0 & 62.62 & 2345 & 1.085 & 293 \\
\hline 23 & 25 & 0.80 & 24.6 & 7.53 & 5.01 & 67.34 & 91.2 & 67.32 & 2540 & 1.104 & 298 \\
\hline 25 & 27 & 0 & 25 & 7.573 & 5.011 & 67.631 & 91.64 & 67.603 & 2565 & 1.098 & 320 \\
\hline 25 & 27 & 0.26 & 25.52 & 7.53 & 5.01 & 69.54 & 91.2 & 69.52 & 2623 & 1.099 & 303 \\
\hline 25 & 27 & 0.40 & 25.8 & 7.53 & 5.01 & 70.62 & 91.0 & 70.61 & 2664 & 1.104 & 303 \\
\hline 25 & 27 & 0.75 & 26.5 & 7.53 & 5.01 & 71.32 & 91.2 & 71.30 & 2690 & 1.085 & 303 \\
\hline 25 & 27 & 1 & 27 & 7.53 & 4.99 & 72.60 & 91.30 & 72.58 & 2720 & 1.077 & 324 \\
\hline \multicolumn{12}{|c|}{$M_{\text {dcp }}$ Alloys $A a, Z=4$} \\
\hline 16 & 18 & 0.40 & 16.8 & 7.39 & 5.00 & 47.01 & 91.20 & 47.00 & 1737 & 1.102 & 253 \\
\hline 18 & 20 & 0.36 & 18.72 & 7.44 & 5.01 & 52.00 & 91.30 & 51.99 & 1938 & 1.104 & 268 \\
\hline 22 & 24 & 0.37 & 22.74 & 7.53 & 5.03 & 62.59 & 91.00 & 62.58 & 2370 & 1.114 & 308 \\
\hline 26 & 28 & 0.61 & 27.22 & 7.53 & 5.01 & 73.96 & 91.00 & 73.95 & 2790 & 1.096 & 308 \\
\hline \multicolumn{12}{|c|}{$\mathrm{O}_{\mathrm{p}}$ Alloys $\mathrm{Pca}_{1}, \mathrm{Z}=4$} \\
\hline $\mathrm{n}_{\mathrm{A}}$ & & $n_{B}$ & $x$ & $\mathrm{n}_{\mathrm{x}}$ & $\mathrm{a}(\AA)$ & $\mathrm{b}(\AA)$ & $c(\AA)$ & $V\left(\AA^{3}\right)$ & & $\mathrm{v}\left(\mathrm{cm}^{3} \cdot \mathrm{g}^{-1}\right)$ & $\mathrm{T}(\mathrm{K})$ \\
\hline 16 & & 17 & 0.70 & 16.7 & 7.43 & 5.01 & 45.55 & 1696 & & 1.082 & 258 \\
\hline 16 & & 18 & 0.60 & 17.2 & 7.41 & 5.00 & 47.44 & 1758 & & 1.089 & 253 \\
\hline 17 & & 18 & 0.40 & 17.4 & 7.47 & 5.02 & 48.44 & 1816 & & 1.113 & 268 \\
\hline 17 & & 19 & 0.30 & 17.6 & 7.43 & 5.01 & 49.27 & 1834 & & 1.111 & 258 \\
\hline 18 & & 19 & 0.20 & 18.2 & 7.46 & 5.01 & 50.04 & 1870 & & 1.096 & 273 \\
\hline 18 & & 20 & 0.15 & 18.3 & 7.43 & 5.01 & 50.77 & 1890 & & 1.102 & 268 \\
\hline 18 & & 20 & 0.70 & 19.4 & 7.43 & 5.01 & 53.81 & 2003 & & 1.102 & 268 \\
\hline 19 & & 20 & 0.55 & 19.55 & 7.47 & 4.99 & 54.07 & 2015 & & 1.100 & 278 \\
\hline 19 & & 21 & 0.40 & 19.8 & 7.46 & 5.01 & 54.72 & 2045 & & 1.102 & 278 \\
\hline 20 & & 21 & 0.20 & 20.2 & 7.46 & 4.99 & 55.49 & 2066 & & 1.092 & 283 \\
\hline 21 & & 22 & 0.60 & 21.6 & 7.5 & 4.99 & 58.86 & 2203 & & 1.089 & 288 \\
\hline 21 & & 23 & 0.40 & 21.8 & 7.5 & 5.02 & 60.26 & 2269 & & 1.111 & 290 \\
\hline 22 & & 23 & 0.15 & 22.15 & 7.55 & 5.02 & 60.82 & 2305 & & 1.112 & 300 \\
\hline 22 & & 24 & 0.08 & 22.16 & 7.53 & 5.03 & 60.64 & 2297 & & 1.107 & 300 \\
\hline 22 & & 24 & 0.70 & 23.4 & 7.53 & 5.01 & 64.37 & 2428 & & 1.109 & 300 \\
\hline 23 & & 24 & 0.50 & 23.5 & 7.52 & 5.01 & 64.01 & 2412 & & 1.097 & 305 \\
\hline 23 & & 25 & 0.40 & 23.8 & 7.53 & 5.02 & 65.11 & 2461 & & 1.105 & 298 \\
\hline 26 & & 28 & 0.05 & 26.1 & 7.52 & 5.00 & 70.05 & 2634 & & 1.079 & 308 \\
\hline
\end{tabular}

a $\mathrm{V}=$ volume, $\mathrm{v}=$ specific volume, $\mathrm{T}=$ measurement temperature.

Thermodynamic assessments of binary phase equilibria were made for various transitions: the mixed rotator state to liquid ( $\mathrm{R} I \rightarrow \mathrm{L}, \mathrm{R} ॥ \mathrm{I} \rightarrow \mathrm{L})$; the mixed rotator state to mixed rotator state $(\mathrm{R} \mathrm{I} \rightarrow \mathrm{R} \mathrm{II})$; and most of the transitions from the ordered mixed solid state to the mixed rotator state $\left(\mathrm{O}_{\mathrm{p}} \rightarrow \mathrm{R}, \mathrm{M}_{\mathrm{dcp}} \rightarrow \mathrm{R}\right.$, and $\mathrm{M}_{\mathrm{dci}} \rightarrow$ $\mathrm{R})$. The modeling of the phase equilibria is founded on the concepts of isomorphism and crossed-isopolymorphism. ${ }^{42,43}$ The computations are based on the equal-G curve method; ${ }^{44}$ a detailed account of the methodol ogy has been given recently. ${ }^{45}$

The transition properties of the pure component substances as a function of chain length, and used for the

(42) Pardo, L C.; Barrio, M.; Tamarit, J . LI.; López, D. O.; Salud, J .; Négrier, P.; Mondieig, D. Phys. Chem. Chem. Phys. 2001, 3 (13), 2644. (43) Pardo, L. C.; Barrio, M.; Tamarit, J . Ll.; Négrier, P.; Lopez, D. O.; Salud, J .; Mondieig, D. J . Phys. Chem. B 2001, 105, 10326.

(44) Oonk, H. A. J.Phase Theory: The Thermodynamics of Heterogeneous Equilibria; Elsevier Science Publishers: Amsterdam, 1981. (45) Rajabalee, F.; Métivaud, V.; Mondieig, D.; Haget, Y.; Oonk, H. A. J. Chem. Mater. 1999, 11, 2788. computations, have been established by means of a gl obal analysis of the set of binary systems. The relationships are

$$
\begin{aligned}
& T_{R \| \rightarrow L}=\left(152.16+11.168 n-0.1679 n^{2}\right) \mathrm{K} \text {; } \\
& \Delta \mathrm{H}_{\mathrm{RII} \rightarrow \mathrm{L}}=(-10.60+2.720 \mathrm{n}) \mathrm{kJ} \cdot \mathrm{mol}^{-1} \\
& \mathrm{~T}_{\mathrm{R} 1 \rightarrow \mathrm{L}}=\left(66.14+21.404 \mathrm{n}-0.4628 \mathrm{n}^{2}\right) \mathrm{K} \text {; } \\
& \Delta \mathrm{H}_{\mathrm{R} \mid \rightarrow \mathrm{L}}=\left(-27.23+5.611 \mathrm{n}-0.1003 \mathrm{n}^{2}\right) \mathrm{kJ} \cdot \mathrm{mol}^{-1} \\
& \mathrm{~T}_{\mathrm{R} I \rightarrow \mathrm{R} I I}=\left(324.31-2.497 \mathrm{n}+0.0964 \mathrm{n}^{2}\right) \mathrm{K} \text {; } \\
& \Delta \mathrm{H}_{\mathrm{RI} \rightarrow \mathrm{RII}} \approx 0.34 \mathrm{~kJ} \cdot \mathrm{mol}^{-1} \\
& \mathrm{~T}_{\mathrm{M}_{\mathrm{dc}} \rightarrow \mathrm{R}}=\left(103.05+13.754 \mathrm{n}-0.2033 \mathrm{n}^{2}\right) \mathrm{K} \\
& T_{M_{d c p} \rightarrow R}=\left(76.66+14.900 n-0.2143 n^{2}\right) K \\
& \mathrm{~T}_{\mathrm{M}_{\mathrm{dcp}} \rightarrow \mathrm{R}}=\left(107.63+13.220 \mathrm{n}-0.1911 \mathrm{n}^{2}\right) \mathrm{K} \\
& \Delta \mathrm{H} \Phi_{\text {ord } \rightarrow \mathrm{RI}}=\left(5.44-0.462 \mathrm{n}+0.0462 \mathrm{n}^{2}\right) \mathrm{kJ} \cdot \mathrm{mol}^{-1} \\
& \text { for } \Phi_{\text {ord }} \equiv M_{d c i}, M_{d c p}, O_{p} \text {, and } O_{i}
\end{aligned}
$$



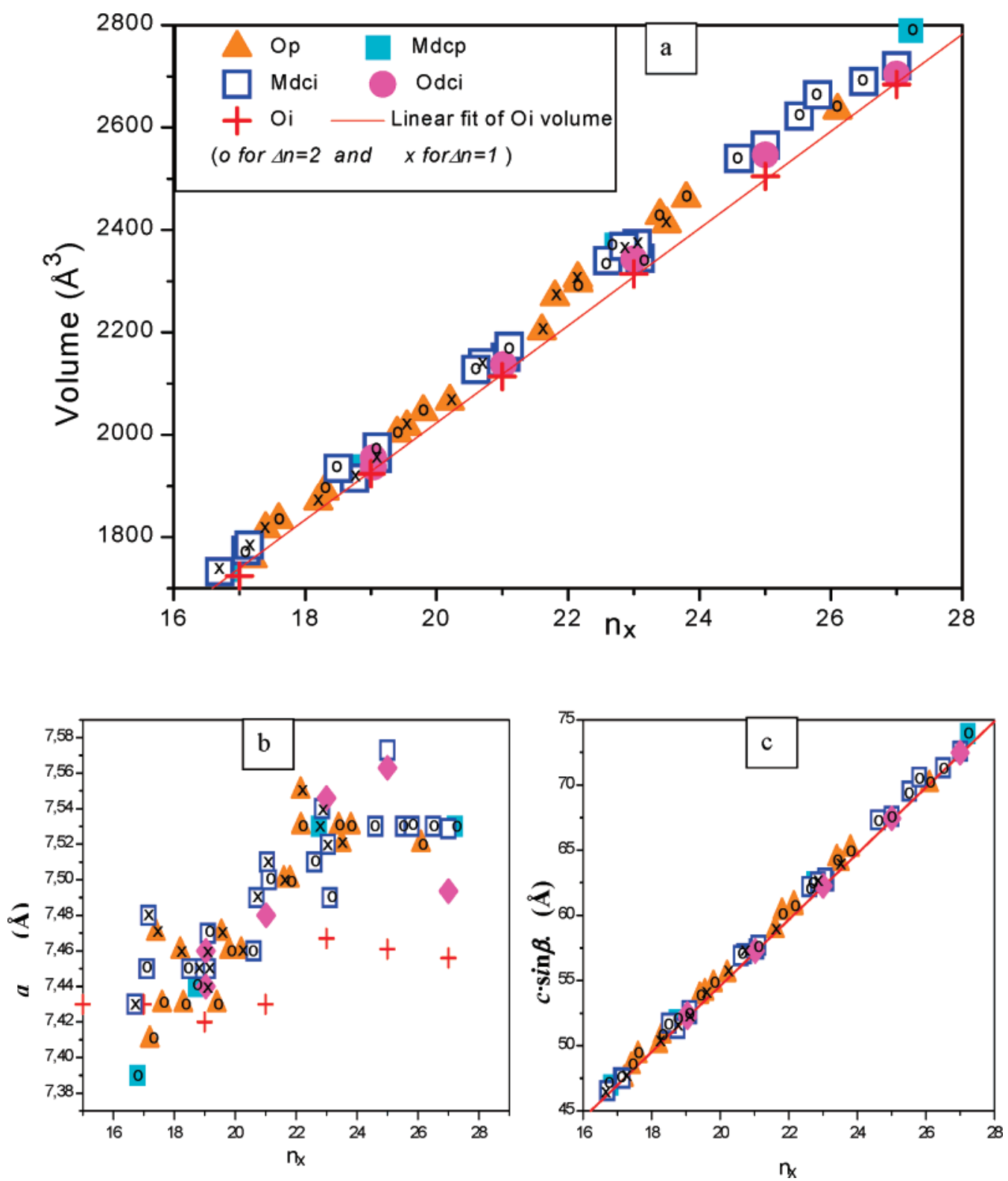

Figure 5. Crystallographic data of ordered phases for mixed crystals $\left(M_{d c i}, M_{d c p}, O_{d c}\right.$, and $\left.O_{p}\right)$ and of pure alkane $\left(O_{i}\right.$ for all the components and $O_{d c i}$ for $n=23,25$, and 27) as a function of $\bar{n}_{x}$ (for an alloy $\left.A_{1-x} B_{x}: n_{x}=x \cdot n_{B}+(1-x) \cdot n_{A}\right)$. (a) Volume; $(b)$ a parameter; (c) c sin $\beta$.

The thermodynamic assessments are carried out for a double reason: to verify the experimental data and to use the available data for calculating the thermodynamic mixing properties. With regard to the mixing properties, we have demonstrated, in a number of publications, that the mixed crystalline states-in a variety of materials (molecular, ionic, and metallic)can be conveniently described by the AB $\theta$ model for the excess Gibbs energy

$$
\mathrm{G}^{\mathrm{E}}(\mathrm{T}, \mathrm{x})=\mathrm{A}\left(1-\frac{\mathrm{T}}{\theta}\right)[1+\mathrm{B}(1-2 \mathrm{x})]
$$

of which the corresponding expressions for the excess enthalpy (heat of mixing) and excess entropy are

$$
\begin{aligned}
& H^{E}(T, x) \rightarrow H^{E}(x)=A[1+B(1-2 x)] \\
& S^{E}(T, x) \rightarrow S^{E}(x)=\frac{A}{\theta}[1+B(1-2 x)]
\end{aligned}
$$

The model is such that the excess enthal py and excess entropy are independent of temperature. The parameter $A$ is a measure of the magnitude of the excess functions. Its value can be correlated to the mismatch in molar volume, or a related property, between the components of a given binary system. For the alkanes, the mismatch parameter we use is the relative difference in chain length, $\Delta n / \bar{n}$. The parameter $B$ is a measure of the asymmetry of the excess functions; its value is on the order of 0.2 . The parameter $\theta$ has the property that, within a family of mixed crystals, it is system-independent. In other words, it has a value that is characteristic for the family as a whole. Families of mixed crystals, therefore, are classes of similar systems in terms of enthal py/entropy compensation:21,22 at the compensation temperature, $\theta$ excess enthalpy and excess entropy compensate one another, such that the excess Gibbs energy is zero (or rather goes through zero). 


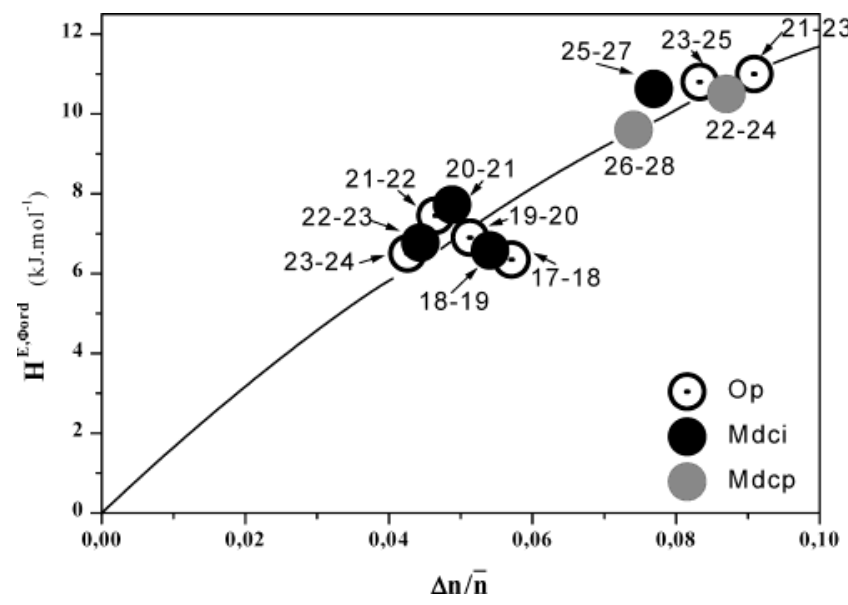

Figure 6. Excess enthalpy of the mixed-crystalline $\Phi_{\text {ord }}$ phases as a function of the relative difference between the number of carbon atoms in the molecules of the components of the system.

The thermodynamic excess properties of the rotator forms RI and RII are that similar that they can be described by the same expression for the A parameter, which is

$$
A^{R}=\left\{51.09\left(\frac{\Delta n}{\bar{n}}\right)+376.5\left(\frac{\Delta n}{\bar{n}}\right)^{2}\right\} \mathrm{kJ} \cdot \mathrm{mol}^{-1}
$$

The family characteristic temperature of the $(\mathrm{R} I+\mathrm{R} ॥)$ family is $\theta=320 \mathrm{~K}$.

For the "ordered forms"22 the situation is such, that, given the limited regions of their existence, the experimental information does not allow distinction to be made among $O_{p}, M_{d c p}$, and $M_{d c i}$. The group of forms is characterized by the characteristic temperature of $\theta=$ $335 \mathrm{~K}$. Their A parameter is given by (Figure 6)

$$
A^{\Phi_{\text {ord }}}=\left\{660\left(\frac{\Delta \mathrm{n}}{\bar{n}}\right)-1903\left(\frac{\Delta \mathrm{n}}{\bar{n}}\right)^{2}\right\} \mathrm{kJ} \cdot \mathrm{mol}^{-1}
$$

\section{Discussion}

The study of the 19 binary phase diagrams of $n$ alkanes with $\Delta \mathrm{n}=1$ and $\Delta \mathrm{n}=2$ converges to a coherent result. Although the intermolecular interactions invariably have the same characteristics, the polymorphism of the alkanes is complex, and that of their mixed crystals even more. Mixing stabilizes various additional phases, which we have all identified: the Rı rotator form at high temperature and the "ordered" (i.e., without disorder of rotation) $\mathrm{O}_{\mathrm{dc}}, \mathrm{M}_{\mathrm{dc}}, \mathrm{M}_{\mathrm{dc}}$, and $\mathrm{O}_{\mathrm{p}}$ forms at low temperature. As a consequence, most of the binary phase diagrams have a considerable number of singlephase and two-phase regions.

For the rotator phases, there is total miscibility when the components have the same, stable phase. For the ordered phases, isomorphism between the two components exists only for $\Delta \mathrm{n}=2$ systems. Notwithstanding high degrees of crystalline isomorphism ${ }^{46}-\epsilon_{m}^{i}\left(O_{i}\right)$ and $\epsilon_{m}^{i}\left(T_{p}\right) \quad(>0.9$ for $n \geq 20$ )-their miscibility is very limited, owing to the appearance of additional phases. The existence of these additional phases is related to

(46) Haget, Y.; Bonpunt, L.; Michaud, F.; Négrier, P.; CuevasDiarte, M. A.; Oonk, H. A. J . J . Appl. Crystallogr. 1990, 23, 492. the presence of different types of defect, favored by the mismatch in size of the molecules in the crystal.

One of the important findings is that mixing is stabilizing forms that for unmixed alkanes become stable, for the first time, at higher values of temperature or chain length. As an example, the Rı rotator form appears in alloys at lower temperatures than for the pure components, and it is encountered already in the $\mathrm{C} 14+\mathrm{C} 16$ system, whereas for the pure even alkanes it makes its first appearance at $n=22$. One could say that conformational and rotational disorder are catalyzed by substitutional disorder.

It is known that, in the short alkanes, and in the lowtemperature phases $\left(\mathrm{O}_{i}\right.$ and $\left.\mathrm{T}_{p}\right)$, chains adopt an overall trans configuration. When the temperature rises and the chain lengths increase, and because the molecules are not rigid, conformational defects (end gauche, kink, double gauche, etc.) make their appearance. When the concentration of conformational defects is high, the mol ecules can no longer be considered as flat. F or C23, C25, and C27, the defects are mainly end-gauche ones, found at the lamellar surface. As a result, a disruption occurs in the packing of chain ends-between mol ecular layers-affecting the interlamellar packing. At a certain temperature, the augmentation of the concentration of defects undergoes a jump (also accompanied by a jump in the interlayer spacing ${ }^{29}$ ) and a solid-solid transition takes place ${ }^{28,30,47}$ This is responsible for the solid-sol id transitions $\left(\mathrm{O}_{\mathrm{i}} \rightarrow \mathrm{O}_{\mathrm{dci}} \rightarrow \mathrm{M}_{\mathrm{dci}}\right)$. For an odd alkane, it is the same sequence of phases that occurs when the concentration of foreign molecules in the host crystal increases. One can say that the increase of intrinsic defects ( $x=0$ or 1 , rise in temperature) and extrinsic defects (given temperature, rise in composition) result in the same sequence of solid ordered forms. For an even alkane, the increase of concentration of foreign molecules in the host crystal induces the appearance of the orthorhombic $\mathrm{O}_{\mathrm{p}}$ phase (al so observed as a metastable form in even alkanes with longer chains, from C28 on, 40 the stable form being monoclinic M 011). The orthorhombic phase has been obtained by crystallization from the melt ${ }^{40}$ and from high-boiling petroleum ether solutions. ${ }^{39}$ The orthorhombic $\mathrm{O}_{p}$ form is also observed near the equimol ecular composition in odd + odd $\left(C_{2 p-1}+C_{2 p+1}\right)$ systems. At the equimolecular composition, the statistical molecular entity is very similar to the even alkane $\mathrm{C}_{2 \mathrm{p}}$. It appears that the end-gauche defects, due to the geometrical mismatch between the molecules, give rise to a different symmetry, which is the orthorhombic form $\mathrm{Pca}_{1}, \mathrm{Z}=4$ observed in higher even alkanes.

The interpretation of the various equilibria has been based on the concepts of isopolymorphism and crossed isopolymorphism. Thermodynamic assessments of phase equilibria in the binary systems were performed successfully, for numerous transitions, including $\Phi_{\text {ord }} \rightarrow R$. The thermodynamic analysis leads to correlations between characteristics of mixed crystals and properties of pure components. F or the complete set of 19 binary systems we applied a uniform thermodynamic description, referred to as the $A B \theta$ model. The $A$ parameter of the model, reflecting the excess enthalpy, is systemdependent, such that it can be correlated to the mis-

(47) Snyder, R. G.; Maroncelli, M.; Qi, S. P.; Strauss, H. L. Science 1981, 214, 188. 
match in chain length. F or the $\Phi_{\text {ord }}\left(\mathrm{O}_{\mathrm{p}}, \mathrm{M}_{\mathrm{dci}}\right.$, and $\left.\mathrm{O}_{\mathrm{dci}}\right)$ mixed crystals $A$ is given by eq 2 and for the $R$ ( $R$ I and Rı) mixed crystals by eq 1 . The $\theta$ parameter of the model is a characteristic property of a family of systems. The $\Phi_{\text {ord }}$ systems are characterized by $\theta=335 \mathrm{~K}$ and the rotator ones by $\theta=320 \mathrm{~K}$.

From an application point of view, the alkane systems correspond to a class of high-performance MAPCM (molecular alloy phase change materials). Over a large range of temperature, materials are available that combine a narrow thermal window (the solid-liquid loops are very narrow) with a high value for the heat of phase change. Applications are found in the fields of thermal protection and storage of energy.

CM031169P 